Instructions for authors, subscriptions and further details:

http://brac.hipatiapress.com

\title{
El Disfraz Comunitario del Arte en el Espacio Urbano.
} Kléver Vásquez Vargas ${ }^{1}$

1) Professor at the Faculty of Architecture and Urbanism of the Central University of Ecuador.

Date of publication: February $3^{\text {rd }}, 2022$

Edition period: February 2022 - June 2022

To cite this article: Vásquez-Vargas, K. (2022). El Disfraz Comunitario del Arte en el Espacio Urbano. Barcelona, Research, Art, Creation, 10(1), 3863. doi: $10.17583 /$ brac. 6685

To link this article: https://doi.org/10.17583/brac.6685

\section{PLEASE SCROLL DOWN FOR ARTICLE}

The terms and conditions of use are related to the Open Journal System and to Creative Commons Attribution License (CC-BY). 
BRAC - Barcelona Research Art Creation. Vol. 10 No. 1, February 2022, pp. 38-63

\section{The Community Disguise of Art in Urban Space}

Kléver Vásquez Vargas

Professor at the Faculty of Architecture and Urbanism of the Central University of Ecuador.

(Received: 19 September 2020; Accepted: 12 September 2021; Published: 3 February 2022)

\section{Abstract}

The following study focused on the artistic practices developed in the urban space by artists and cultural managers who are involved with the social and community life of vulnerable and excluded groups. The projects presented at "Encuentros de arte urbano y comunitario al zur-ich" (2002-2018) were studied; carried out in the south of Quito-Ecuador; sector of popular, worker and peasant extraction. The artistic projects were measured and analyzed in their communicational and spatial aspects, based on the categories that James Scott found in the political practices of the "dominated", and relating them to the spatial delimitation that, according to Michel de Certeau, produces the story as a travelogue. The results showed an urban space "hidden" in the community, where their practices, with their own aesthetic characteristics, evoke the link between art and politics.

Keywords: Community art, urban, rural, border, dissent 
BRAC - Barcelona Research Art Creation. Vol. 10 No.1, February 2022, pp. 38-63

\section{El Disfraz Comunitario del Arte en el Espacio Urbano}

Kléver Vásquez Vargas

Docente de la Facultad de Arquitectura y Urbanismo de la Universidad Central del Ecuador.

(Recibido: 19 setiembre 2020; Aceptado: 12 setiembre 2021; Publicado: 3 febrero 2022)

\section{Resumen}

El siguiente estudio se enfocó en las prácticas artísticas desarrolladas en el espacio urbano por artistas y gestores culturales que se involucran con la vida social y comunitaria de grupos vulnerables y excluidos. Se estudiaron los proyectos presentados en los "Encuentros de arte urbano y comunitario al zurich" (2002-2018); realizados en el sur de Quito-Ecuador; sector de extracción popular, obrera y campesina. Los proyectos artísticos se midieron y analizaron en su aspecto comunicacional y espacial, basándose en las categorías que James Scott encontró en las prácticas políticas de los “dominados", y relacionándolas con la delimitación espacial que, según Michel de Certeau, produce el relato como relato de viaje. Los resultados dieron cuenta de un espacio urbano "oculto" en lo comunitario, donde sus prácticas, con características estéticas propias, evocan el vínculo existente entre arte y política.

Palabras clave: Arte comunitario, urbano, rural, frontera, disenso 


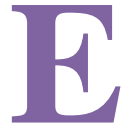

1 estudio trata sobre la relación del espacio urbano y un tipo de arte con características propias de las ciudades en los países andinos, donde la ciudad y el campo están íntimamente relacionados. Para abordar el problema es necesaria la distinción campo-ciudad, sabiendo que dicha distinción fue profundizada por la sociología clásica, sobre todo, aquella influenciada por Ferdinand Tönnies y su "Comunidad y Sociedad" publicada en 1887, en donde se plantea que las relaciones sociales son una creación de la voluntad humana, distinguiendo una voluntad esencial propia de los campesinos y artesanos de una voluntad arbitraria propia de los hombres de negocios o científicos (Gómez, 2001). Por otro lado, esa dicotomía resulta útil para explicar el fenómeno del arte moderno al cual, eventualmente, se adhieren o rechazan las manifestaciones artísticas de la actualidad; entendiendo que el arte moderno fue vinculado directamente como producto de la ciudad, diferenciándose por ello de otras manifestaciones estéticas foráneas a lo urbano, inaugurando, de esa manera, un centro y una periferia artísticas. Sin embargo, dicha distinción ciudad-campo o centro-periferia, en la actualidad, sólo nos permite dilucidar los conflictos o las tensiones que pueden entreverse en su interrelación, donde además, lo local y lo global constantemente se superponen, acortando o eliminando las distancias cuando "lo lejano se entrelaza en nuestro (lugar) "local"” (Massey, 2008, p.118). Provocando, además, entre otras cosas, lo que García Canclini (1989) llamó "fronterización del mundo cultural", es decir, la asimilación de códigos culturales diversos que hace "más pequeñas las ciudades, las convierte en aldeas en el contexto de una circulación de elementos materiales e imaginarios provenientes del mundo entero. (...) -Se trata de ciudades fragmentadas en pequeñas comunidades debido a- la ausencia de un ambiente cosmopolita capaz de acoger la diversidad" (Kingman y Bretón, 2016, p.251).

La distinción entre ciudad y campo nos deja comprender un poco más al arte moderno como arte de la ciudad, encasillando a la producción estética del campo y relacionándola con la artesanía (Durkheim, 2014, p.52) y, por lo tanto, considerando idealmente al campo como una estructura definida y cerrada, cuya relación social se sostiene en la consanguineidad y el parentesco; un alfarero transmite sus conocimientos a sus hijos y estos continúan con dicha labor sin pretender superarla o cambiarla. Los hijos no quieren ser mejor que sus padres, simplemente perfeccionan una misma labor. Esa sería la estructura social que fundamenta a la práctica artesanal y a sus objetos. Por el contrario, esa artesanía se diferencia del arte moderno porque éste, desde su origen, buscó la originalidad y la novedad, pretendiendo 
mantener un constante cambio o progreso en sus manifestaciones y, en consecuencia, rechazando las estructuras conservadoras del campo. Dicho progreso y originalidad podían descubrirse en las ciudades; pues, es ahí donde los extraños se encuentran; extraños que no comparten vínculos de parentesco e interactúan basados en relaciones contractuales; es decir, cambiando la relación consanguínea y afectiva del campo por el vínculo contractual e intelectual de la ciudad (Simmel, 1977). Esta diferenciación respondería directamente a la clasificación que Ferdinand Tönnies hiciera en su "Comunidad y Sociedad" (1887).

En el espacio público de la ciudad nadie se conoce, comparten a su vez, un mismo grado de anonimato. En las primeras metrópolis confluyeron las primeras multitudes de hombres y mujeres anónimos, muchos de ellos migrantes, los cuales, habían dejado atrás, en sus lugares de origen, los espacios y personas familiares; es decir habían dejado aquello que les dotaba de identidad y destino. En la ciudad moderna no están sujetos al lazo comunitario que les otorga un rol social predestinado; son libres y por ello, se ven obligados a forjarse una identidad y rol social (Simmel, 1997); lo harán, entre otras formas, a través de la excentricidad y originalidad; valores propios del arte moderno. La dinámica social propia de las ciudades influyó en el arte, posibilitando el surgimiento de las vanguardias europeas, lo que significó que el arte llegue a identificarse con cualidades propias de lo urbano; es decir, con todo aquello que "no está constituido por estructuras estables, sino más bien por un orden de relaciones sociales por lo general impersonales, superficiales y segmentarias" (Delgado, 2007, p.182). Así es como, el arte moderno y el espacio urbano comparten esa condición de estabilidad efímera, de cambio perpetuo y continuo movimiento. Desde que Marinetti entonó su canto a "las mareas multicolores y polifónicas" de las capitales modernas y a las "estaciones ávidas de serpientes que humean", el arte o, buena parte de sus expresiones, ha ido modificando su condición material y temporal llegando a convertirse en manifestaciones efímeras o inasibles como lo demuestran algunos ensayos que hacen referencia a la cualidad "líquida" o "gaseosa" del arte contemporáneo (Bauman, 2007; Michaud, 2007) compartiendo así, la inestabilidad y transitoriedad propias de lo urbano.

Es así que, existen momentos en la ciudad cuando el arte, simplemente, acontece e irrumpe en sus calles como si de un juego que interfiere con las labores cotidianas se tratara; son momentos lúdicos alguna vez buscados y catalogados como situaciones. De esa manera; arte y ciudad pueden encontrarse desinteresadamente en la calle, y entablar por instantes, vínculos parecidos a lo que E. Goffman (1997) denominó “desatención cortés"; 
interacción social propia del espacio público que disfraza y encubre en sus formas la incomodidad o amenaza que puede representar el encuentro con minorías culturales, étnicas o religiosas. En el espacio público entonces, pueden disfrazarse de ciudadano las diferencias de clase y las relaciones de poder (Delgado, 2011). El disfraz del ciudadano ocupa un espacio público que adquiere rasgos estéticos genéricos y globales, similares a los que Byung-Chul Han (2018) describe como propios de la cultura contemporánea de la positividad, que oculta en su disfraz terso, pulcro y pulido cualquier rastro de negatividad que pueda terminar conmocionando o perturbando (exigencia que, por el contrario, Gadamer reclama para todo arte) la tranquilidad y seguridad que el ciudadano demanda para el espacio público; llegando a ocultar, a su vez, la negatividad representada por un "otro". Es decir, la estética buscada para el espacio público extrae de la vida urbana únicamente su apariencia conveniente a la promoción mercantil y evita la compleja interrelación social que la diversidad cultural puede presentar cuando vive plenamente el espacio urbano.

Para Gadamer (1991) el arte no se separa de la vida, y su condición estética se expresa, al igual que los acontecimientos urbanos; en momentos. Son momentos que se desprenden de un tiempo lineal y acumulativo para mostrarnos lo particular y extraño, sugiriéndonos, eventualmente, lo eterno. Así, el arte y la vida se manifiestan en el juego como un movimiento sin meta y sin fin, que busca su significado a través de lo simbólico como aquello particular que representa lo universal; es decir que, el juego artístico busca "captar la permanencia en lo fugitivo", entendiendo al arte como superación del tiempo, introduciendo el concepto de fiesta como ruptura del presente y haciendo de la experiencia estética un "tiempo de celebración" o un momento festivo. Juego, símbolo y fiesta que se relacionan con el arte moderno, cuyas manifestaciones, siempre lúdicas, para Bolívar Echeverría (2010), se basan o tienden a combinarse, incluso confundirse, con el ritual y la ceremonia festiva que, por otro lado, también pertenecen la cultura barroca; cultura que ha adquirido características propias en los países sudamericanos y, especialmente andinos, donde acompañó sus procesos de independencia y modernización.

En Ecuador como en algunas ciudades andinas, la modernidad se hizo patente en sus ciudades principales; en ellas, la sociedad pudo manifestar su condición moderna que, para Eduardo Kingman (2016), no resulta de la expresión de la élite dominante; la cual vivía arraigada en practicas sociales conservadoras herederas del mundo de la hacienda y para quienes la modernidad se expresó de manera epidérmica en las formas arquitectónicas y de ciudad; sino más bien, en esa "otra" modernidad que se dio en los "trajines 
callejeros" de "los sectores populares que lograron desarrollar su propia política de la vida cotidiana" (Kingman, 2016, p.300), configurando nuevos sentidos y formas de percepción en la convivencia urbana entre el campo y la ciudad pues, no llegaron a desligarse de los elementos culturales pertenecientes al mundo indígena del que provenían (Kingman y Bretón, 2016, p.250). Considerando esas características urbanas de la ciudad andina, no se puede asegurar la existencia de una división categórica entre el campo y la ciudad, ya que, en esas condiciones, las viejas dicotomías "dejaban de funcionar y se formaban "paisajes culturales intermedios," o "zonas de frontera" entre lo blanco y lo indígena." (Kingman y Bretón, 2016, p.239). Esa condición hibrida de la ciudad se acrecienta a la vez que se fragmenta con la expansión urbana que las ciudades latinoamericanas han experimentado en las últimas décadas, resumida en "una nueva forma de separación de funciones y elementos socio-espaciales, en la que las actividades productivas y usos residenciales se dispersan en las áreas de la periferia urbana" (González, 2012, p.99), y cuyos fenómenos pueden estar englobados en lo que se conoce como "nueva ruralidad" (Gómez, 2001; Kay, 2007), donde la ciudad pierde especificidad como unidad geográfica, económica, política y social (Soja, 2008).

De esa manera, la ciudad andina se llenó de campesinos para construir su modernidad con "trajines callejeros", así como de élites con disfraz moderno que mantienen relaciones sociales acarreadas de la Colonia y propias de la hacienda. En otras palabras, el campo, y todas las tensiones que estimula, se ha mantenido presente en la ciudad desde su fundación, y se lo puede intuir, entre otras cosas, a través de sus formas de relación comunitaria, las mismas que refuerzan la identidad indígena, sobre todo, a través de las organizaciones y los movimientos indígenas que, desde los años 80 actúan en respuesta a las políticas neoliberales, mismas que reemplazaron a los intentos latinoamericanos de reforma agraria (Kay, 2007). Esas políticas promueven el surgimiento de las "nuevas ruralidades que postulan representaciones y usos de lo rural no necesariamente anclados en la producción agropecuaria. [Y, por tanto,] atravesadas por la dimensión simbólica que descubre/construye nuevos atractivos en lo rural." (González, 2012, p.100-101). Algunos de ellos como prácticas vinculadas al "juego, la fiesta y el arte" en las comunidades; es decir, tomando en cuenta lo diverso y, por ello, pudiendo inscribirse en lo que se conoce como "multiculturalismo" que, a la larga, termina centrando su mirada en el potencial económico que puede representar la alteridad cultural. (Comaroff, 2011). Después de todo, "el modo de producción capitalista, desde 
su inicio (economía monetaria y mercantil), convulsionó profundamente las estructuras agrarias, desde dentro y desde fuera" (Lefebvre, 1978, p.74).

Diferentes manifestaciones artísticas han buscado adoptar el carácter comunitario que, se supone, está presente en los barrios y comunidades aledaños o periféricos a la urbe que, a su vez, presentan un marcado contexto rural. El arte, en esas condiciones, pretende involucrarse con las prácticas sociales existentes, asemejándose, de alguna manera, a las expresiones artísticas empezadas con el specific art o el arte contextual de Paul Ardenne (2006) que, a partir de los años sesenta y setenta desarrollaron todo un material discursivo "que cuestionaría no sólo el objeto de arte, sino el espacio en que operaba y el diálogo con el contexto en el que se insertaba" (Segura-Cabañero y Simó-Mulet, 2017, p.221). Aquello, sumado a las expresiones que acentuaron el aspecto social y comunitario de, por ejemplo, la estética relacional de Nicolas Borriaud (2008), pudieron abrir y expandir las fronteras del campo del arte. Disolución de los límites artísticos que, según Claire Bishop (2006), obligaba a sacrificar las ideas estéticas y tradicionales del arte, así como el idealismo romántico que puede surgir cuando el arte se compromete socialmente. Dicho compromiso social implicaría "trabajar por una cultura más accesible, participativa, descentralizada y que refleje las necesidades y particularidades de las diferentes comunidades" (Palacios, 2009, p.199). Es decir, manifestar los principios de las prácticas artísticas colaborativas o del arte comunitario, el cual, en relación al teatro, por ejemplo, "nace de la voluntad comunitaria de reunirse, organizarse y comunicarse, parte de la idea de que el arte es un agente de transformación social" (Greco, 2007, p. 44) y, por ello, un agente político en el sentido del "activismo artístico", el cual, no trata simplemente de hablar de lo político o de darle a lo político un cariz estético sino de "hacer lo político" (López y Bermúdez, 2018, p.22); puesto que, "si el arte comunitario es algo, es la manifestación de una ideología” (Morgan, 1995, p.18).

Confluyen así, en un espacio urbano fronterizo, las formas políticas que adquieren las relaciones de poder y los discursos globales con las formas heterogéneas de relación urbano-campesina. Y, de esa manera, posiciones antagónicas se encuentran en el espacio urbano, habitando disfrazadas la ciudad y haciendo que, por ello mismo, surjan las maneras o, lo que James Scott (2000) llamó, discursos ocultos, de quienes son considerados dominados o subalternos. Formas que, según Scott (2000), construyen los dominados para poder tener voz propia. Formas construidas en espacios cotidianos y domésticos que, eventualmente, se dejan entrever en un espacio público periférico, liminal o fronterizo. Se trata, entonces, de indagar en las formas 
que han sabido adaptarse, no sin resistencia, a los discursos dominantes de la urbe sin perder de vista su condición rural o campesina. Así, en esos lugares, un arte con disfraz comunitario se inserta en lo rural, el mismo que siempre supo camuflarse en la ciudad. Ese dialogo de máscaras manifiesta su condición conflictiva y política, ubicando sus tensiones en las fronteras de lo urbano, allí, donde se desvanecen los límites que separan al arte urbano del comunitario.

\section{Confeccionando el Disfraz}

Para averiguarlo estudiamos las intervenciones artísticas de los encuentros de arte urbano y comunitario al zur-ich (2002-2013), realizados al sur de Quito, precisamente en los barrios y comunidades de origen obrero y campesino; es decir, con las poblaciones, generalmente, desfavorecidas de la ciudad. Intervenciones gestionadas por el colectivo artístico de gestión cultural "Tranvía Cero". Este colectivo, como tantos otros, se formaron al unirse y afrontar la crisis del "Feriado Bancario" de 1999, "el cual afectó a varios sectores del país -sobre todo al arte-" (Puebla en Almeida, 2018, p.46). Por ello y por:

El contexto socio político y cultural atomizado del país (...) creamos espacios disidentes fuera del circuito oficial del arte, los cuales no eran de exposición sino donde se podía entablar relaciones de vida distintas e intentar sostenerlas en el tiempo (aunque a veces podían ser un enésimo salto al vacío). (Tituaña en Almeida, 2018, p.34).

Se realizaron entrevistas con los gestores culturales de "Tranvía Cero", algunos, actualmente, docentes en la Facultad de Artes de la Universidad Central del Ecuador; sin embargo, la fuente principal de la investigación se basó en la documentación del archivo virtual del colectivo, donde se encuentran las descripciones y testimonios de los diferentes proyectos en el año en que se realizaron. Cuarenta proyectos fueron "medidos" desde dos puntos de vista: la condición comunicativa y la producción del espacio. Pero, ambos puntos de vista, siempre comparados o tratados de acuerdo a las "formas elementales del disfraz" de James Scott (2000); es decir, con aquellas maneras que, los dominados, como los llama Scott, disfrazan o encubren ciertos mensajes que, de otro modo, no podrían ser expresados en la esfera pública. Estas formas son: el anonimato, que manifiesta abiertamente el mensaje sin mostrar el rostro del emisor. El eufemismo que dice sin decir, volviendo ambiguo el mensaje y evitando la represalia del receptor. Y el 
refunfuño, cuyo mensaje se expresa como un quejido, un rumor, un gesto que es advertido por el receptor sin ser comprendido del todo.

Estas "formas elementales del disfraz" fueron medidas en cada proyecto artístico en cuanto comunicación y espacio. En lo referente a la condición comunicativa, las formas elementales del disfraz giraron en torno al mensaje y su relación con el emisor y el receptor; es decir, en relación al artista y al público. Así, los proyectos que presentan anonimato serán aquellos en los que el emisor o artista no aparece, mientras que en el refunfuño será el receptor o público quien no aparezca, pasando por la ambigüedad del mensaje o presencia compartida entre el artista y el público en el eufemismo. De esa manera, los proyectos artísticos fueron considerados como relatos, los mismos que, a decir de Michel de Certeau, son el acto creador que funda espacios, donde diferentes acciones se cruzan, pues, "todo relato es un relato de viaje, una práctica de espacio” (de Certeau, 2000, p.128).

\section{La Comunicación y las Formas Elementales del Disfraz}

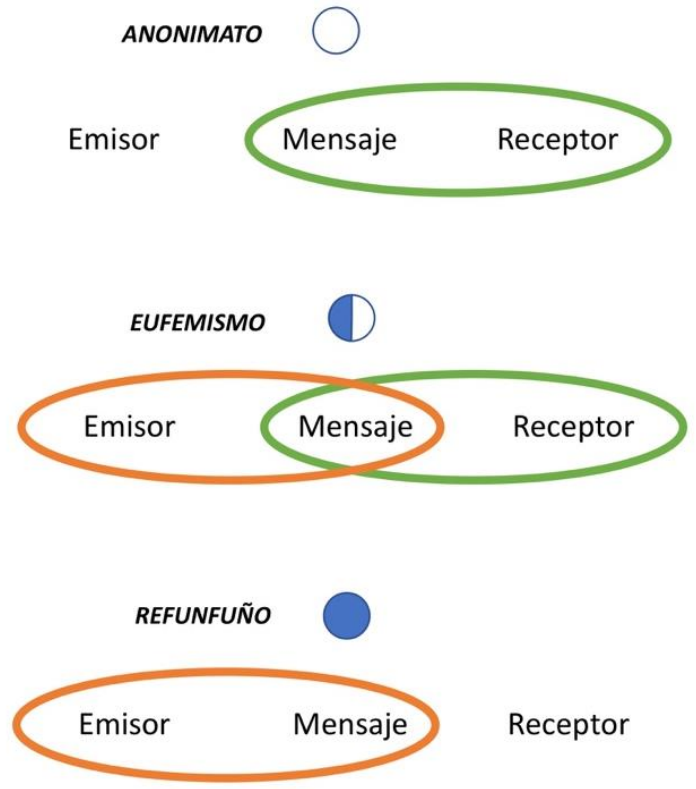

Figura 1. Formas elementales del disfraz en su aspecto comunicativo. Elaboración propia. 
Para De Certeau (2000) se categorizan así tres tipos de espacios delimitados por ese relato de viaje: el establecimiento, el desplazamiento y el rebase de límites (de Certeau, 2000, p.136). Estas tres delimitaciones espaciales producidas por el relato se corresponden a un relato fundador que da paso a la acción humana en tres etapas centrífugas que, por otro lado, hacen referencia a la expansión territorial o espacial de una nación con respecto a un pueblo extranjero: declaración de guerra, expedición militar, alianza con otra nación (de Certeau, 2000, p.136); es una marcha en tres etapas. De esta manera, el establecimiento se remitirá a una interioridad, a un espacio interior; el desplazamiento llevará la expedición a la frontera, a un límite espacial o borde, y el rebase de límites mostrará una exterioridad, una extranjería, un otro. Estos tres tipos de espacio del relato serán relacionados con las tres formas elementales del disfraz antes descritas.

Es así que, presentan anonimato los proyectos de arte en los que se evidencia, en el espacio que produce, prácticas que resultarían extrañas al mismo; prácticas diferentes, totalmente otras. El anonimato transgrede el orden espacial donde se recibe el mensaje, pues representa un otro espacio yuxtapuesto en el espacio receptor, modificando, actualizando o desplazando las posibilidades y prohibiciones organizadas por el orden espacial; actúa como el transeúnte que rebasa los límites de un orden urbano, "transformando en otra cosa cada significante espacial" (de Certeau, 2000, p.110). Se trata de prácticas en el espacio que, en circunstancias corrientes, no se realizarían en ese lugar; prácticas que configuran un espacio que se yuxtapone y encara a la normalidad o el costumbrismo del espacio que lo acoge, interpelándolo quizá.

En el eufemismo, el emisor y el receptor comparten un mensaje encubierto, equidistante semánticamente para ambos, camuflado por la conveniencia de ambos territorios; recorre la frontera que separa al emisor del receptor sin pertenecer por completo a ninguno; mensaje ambivalente que delimita un espacio, a la vez que insinúa su transgresión. Espacio bifronte en plena frontera. La espacialidad de los proyectos de arte urbano señalados por el eufemismo, presentan, en las prácticas y acciones artísticas que se proponen, similitud o analogía con las actividades que cotidianamente se han venido dando. Prácticas similares, pero no iguales, llevando al límite lo cotidiano, mostrando su frontera antes de ser otra práctica. Prácticas que producen un espacio que las acoge casi con naturalidad. Se trata de un espacio que representa prácticas que con el tiempo cambian, evolucionan o se transforman. El tiempo, entonces, también puede producir el espacio del eufemismo. 
Finalmente, el refunfuño que, según Scott "responde más a los intereses de los subordinados que de sus superiores" presenta la particularidad de contenerse en el emisor, en un interior cuyo mensaje no sobrepasa los límites, sino sólo a través de una manifestación corrompida, enredada o alterada, mostrándose simplemente como "un gemido, un suspiro, un quejido, una risa contenida, un silencio oportuno, un guiño o una mirada fija" (Scott, 2000, p.186). Se relacionará directamente con el espacio de la interioridad, el espacio delimitado por un establecimiento. Es decir que, un espacio del refunfuño para el arte surgirá cuando las prácticas artísticas que allí se realicen intensifiquen o, en su defecto, nieguen las prácticas que cotidianamente el lugar admite.

\section{El Espacio y las Formas Elementales del Disfraz}
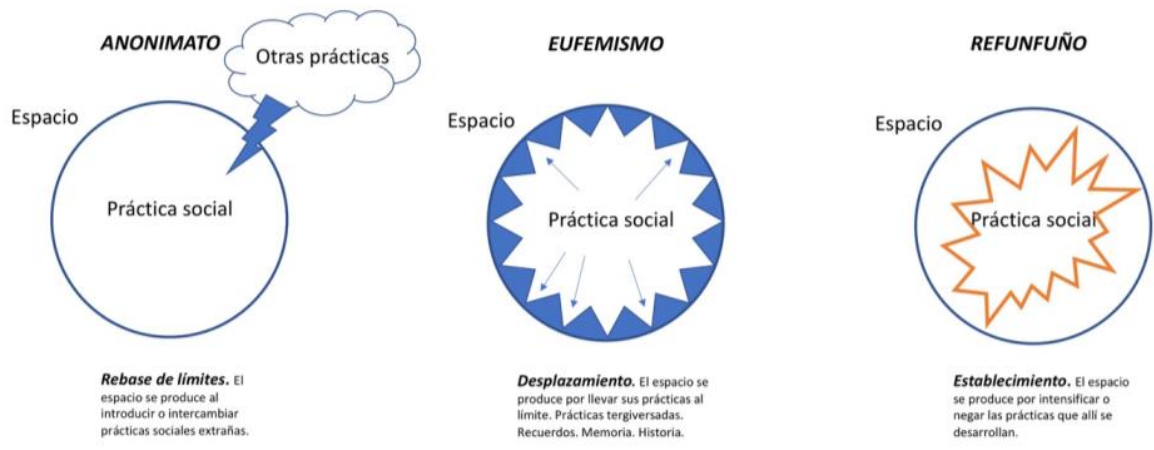

Figura 2. La producción espacial a través de la práctica social del arte. Elaboración propia.

Vemos así que cada proyecto, respondiendo a estas dos vertientes, se bifurca en el análisis; mostrando tanto, su cualidad comunicativa y artística como su potencial espacial y público. Sin embargo; ambos: arte comunitario y espacio público, terminarán entrelazándose debido a la condición social de su mensaje oculto; es decir, con la coincidencia o el encuentro que surja entre lo comunicativo y lo espacial referido a una de las "formas elementales del disfraz".

Para este estudio, el mensaje oculto se vislumbra en la temática abordada; en los temas que se consolidaron con su reiteración y presencia en los diferentes proyectos de arte analizados, pero que, se evidencian en la práctica concreta del proyecto artístico en el lugar que se realiza; es decir, con la 
yuxtaposición entre el tema y el espacio. James Scott recuerda, citando un trabajo de Allon White, que "El espacio discursivo nunca es completamente independiente del lugar social y el surgimiento de nuevos modos de hablar se puede percibir a través de la aparición de nuevos lugares públicos" (Scott, 2000, p.152).

En esos temas que sugiere la comunidad y en la manera cómo el proyecto los encara, se podrán vislumbrar los discursos dominantes que determinan sus prácticas sociales. Desde aquellos discursos que han venido insinuándose en los consecutivos diálogos que el colectivo "Tranvía Cero" entabló con los vecinos, hasta aquellos valores dominantes que la comunidad los repite como suyos, en lo que algunos autores marxistas llaman falsa conciencia (Scott, 2000), naturalizados en el argot popular del cotidiano.

\section{El Mensaje del Disfraz}

En ese sentido, de los cuarenta proyectos analizados, los resultados que suelta el estudio tienen que ver con trece proyectos que presentaron coincidencia entre lo comunicativo y lo espacial, clasificados luego, de acuerdo a las formas elementales del disfraz. A continuación, se exponen tres ejemplos representativos:

\section{Anonimato}

El proyecto de Fernando Falconí, consistió en construir colectivamente la imagen de una virgen: "Nuestra Patrona de la Cantera" (2008), en trabajo conjunto con dieciséis trabajadoras sexuales. Este proyecto se desarrolla cuando las trabajadoras sexuales, quienes trabajaban en la plaza 24 de Mayo en el Centro Histórico, fueron trasladadas a un lugar periférico y oculto de la ciudad. En este caso, la construcción de la imagen deviene en acto político en el sentido de Hannah Arendt, pues, la actividad desarrollada normalmente por las trabajadoras sexuales se mantenía oculta en un espacio restringido y privado, y por tanto, toda mujer, quien, "al igual que el esclavo, no se le permitiera entrar en la esfera pública” (Arendt, 2016, p.49) habitaría únicamente la esfera privada del anonimato como todos aquellos humanos que han sido convertidos "en completamente privados, es decir, han sido desposeídos de ver y oír a los demás, de ser vistos y oídos por ellos" (Arendt, 2016, p.67). Sin embargo, al construir la imagen, las mujeres encuentran su discurso público; la imagen habla y ellas a través de la imagen. Acá la imagen es palabra social cuyo mensaje se muestra entero en la práctica que pretende 
ser ritual y por tanto es política porque a la vez que es discurso, provoca también acción (Arendt, 2016).

Representación propia pero, sin embargo, representación extranjera a la actividad común del lugar; es decir, la imagen no representa la actividad del lugar ni su producción espacial, sino tal vez, su opuesto, su contrario interpelante. Se trata de una imagen traída, no de la práctica social, sino de su ideología y creencia; es decir, ha rebasado los límites viniendo de otro lugar. La imagen materializa el espacio de la creencia y se yuxtapone al espacio vivido, al espacio social.

En la imagen se encuentra la contribución y participación de cada uno de los miembros de esa comunidad, cada mujer aportó a la construcción de la imagen con un poco de su creencia, de su fe, con un poco de ese otro espacio que lleva dentro. La imagen así, se vuelve la representación del espacio que acoge los fragmentos ideológicos de cada una de ellas, por tanto, la imagen aglutina en el exterior, en la representación, ese mundo que cada una de ellas lleva en sí por separado. Se vuelve nexo simbólico entre quienes habitan el mismo espacio y las mismas circunstancias, volviendo comunitario su vínculo. No en vano se trata de una imagen que se remite a las imágenes cristianas, ya que "encontrar un nexo entre las personas lo bastante fuerte para reemplazar el mundo, fue la principal tarea política de la primera filosofía cristiana" (Arendt, 2016, p.62).

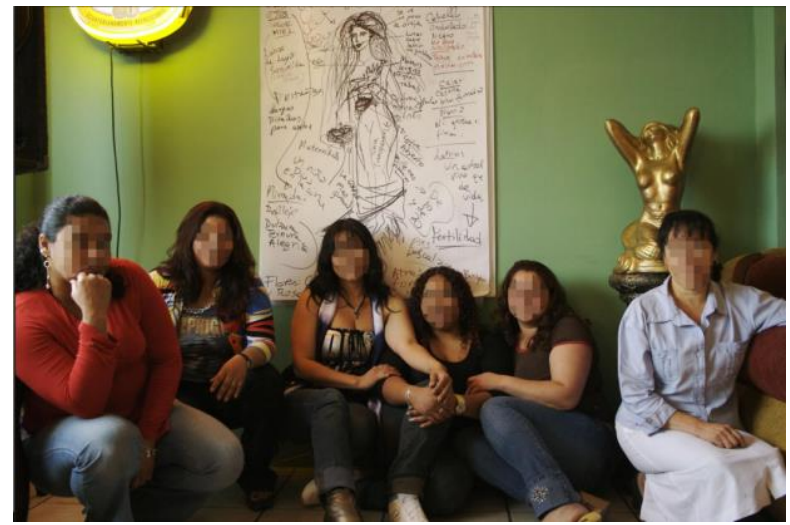

Figura 3. Trabajadoras sexuales en "Nuestra Patrona de la Cantera”, 2008. Fuente: archivo Tranvía Cero.

Entonces ¿los grupos subalternos y periféricos pueden construir imágenes sagradas al igual que el discurso institucional, global y dominante? La práctica social que, a manera de ritual oculto, legitimó la imagen construida por las 
trabajadoras sexuales, nos dice que sí. Por lo tanto, la imagen adquiere un valor simbólico para quienes la portan y la trasladan, llevando su "aura", o su discurso, de forma oculta y no comercial -alejada de los medios de reproductibilidad técnica e informática- a lugares frecuentados por quienes han dejado de ser productivos o requeridos y que, en su expulsión, buscan ahora un lugar propio. Es así que, sus "estampitas" han llegado a ser vistas, a decir del propio Fernando Falconí (entrevistado en el 2019), en los pueblos fronterizos con Colombia y con el Perú.

\section{Eufemismo}

Así mismo, el eufemismo está presente en proyectos como “¿Frontera?" (2008) de Patricio Dalgo. Este proyecto se desarrolla en un momento en el cual, el comercio de cilindros de gas para el consumo doméstico estaba prohibido entre Ecuador y Perú; sin embargo, los habitantes traficaban gas en la frontera a través del contrabando. Patricio Dalgo propone cocinar patatas a un lado de la frontera, e instala un quiosco improvisado con una cocina que se conecta por medio de una manguera a un cilindro de gas ubicado al otro lado de la frontera. Es decir, instala un puente que puede leerse en el sentido de Michel de Certeau, dando cuenta que la frontera tiene un papel mediador; funciona como tercero, es un "intervalo"; un "espacio entre dos" que "crea la comunicación al mismo tiempo que la separación” (de Certeau, 2000, p.139).

El puente puede juntar las poblaciones que las fronteras, producidas por el discurso oficial, históricamente, separaron. El contrabando y el comercio que se realiza en la frontera entre Ecuador y Perú funcionan como puente entre los dos países. La obra de Patricio Dalgo pone en evidencia esa característica ilícita y comercial que ya existe en el lugar, acentuando la ambigüedad, entre comunicación y separación, propia de una frontera; difuminando a la vez, la ya desdibujada línea fronteriza existente entre ambas poblaciones. Quienes habitan la frontera, en cierto sentido, no tienen nacionalidad única, son parte de la ambigüedad del lugar y, aunque su identificación y ciudadanía los ubique en un solo lado de la frontera; de alguna forma, pertenecen a los dos países a la vez. Sus vínculos consanguíneos y afectivos se contraponen a la desvinculación marcada por su ciudadanía y nacionalidad. El artista también se ubica en ese tercer espacio de la ambigüedad pues, con la práctica los habitantes o, mejor dicho, los contrabandistas por un lado y con la ideología del artista por otro lado; ninguno, a su manera, cree en la frontera como borde infranqueable. Ambos (artista y habitante), en cierto modo, comparten las 
identidades posnacionales que cuestionan las estructuras cerradas que pretenden consolidar la idea moderna de nación, patria o Estado.

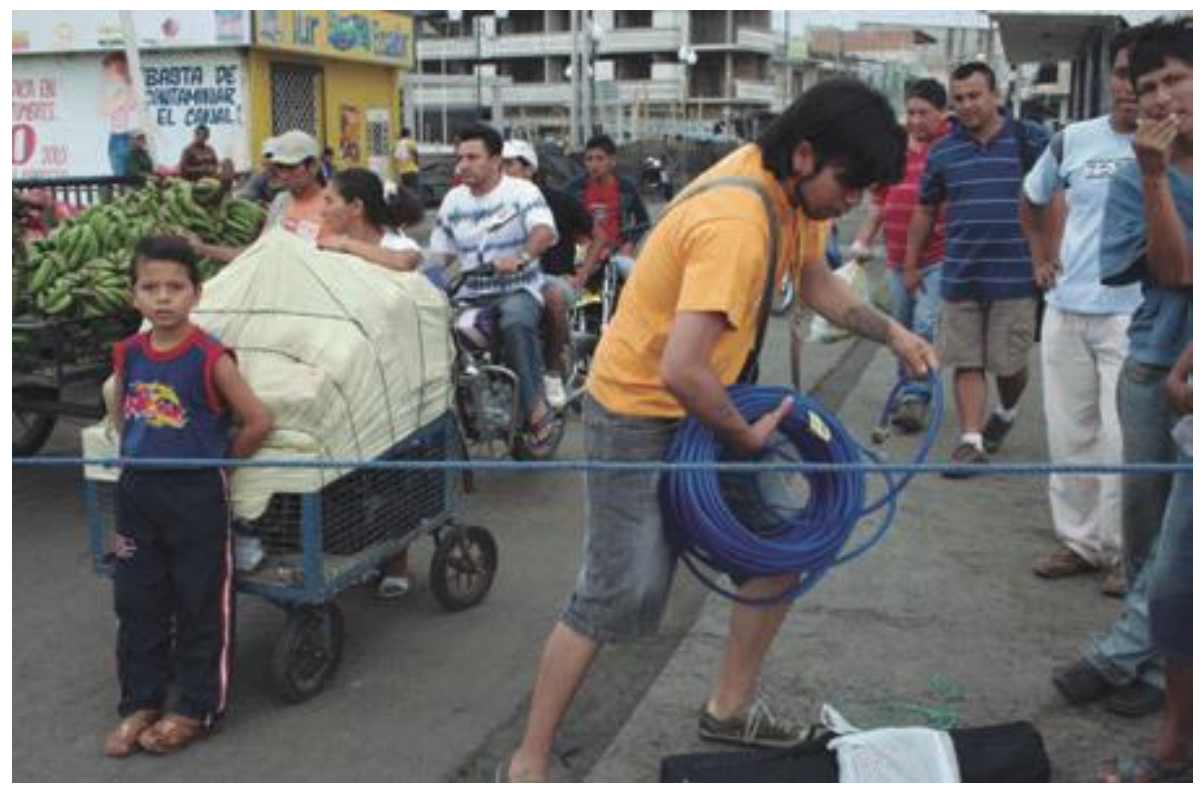

Figura 4: ¿Frontera? Fuente: obtenido del catálogo "al zur-ich 2003-2013" pág. 188

Cuando Patricio Dalgo en su proyecto apela a, según él mismo, la cooperación y fraternidad de quienes transitan y habitan la frontera, da cuenta que existen poblaciones fronterizas que escapan a la lógica mercantilista que polariza a todo individuo extranjero como turista o inmigrante; mostrando que, más allá de un discurso multiculturalista que, a nombre del turismo, pretende eliminar las fronteras para beneficio y flujo del capital (posesión del turista y privación del migrante); éstas pueden estar ahí, no solamente para ser visitadas o atravesadas, sino también, para ser vividas o compartidas de forma comunitaria. Se aleja la obra, de esa manera, del par binario que determina el capital. La obra no comercia el alimento que elabora, pero lo distribuye entre los transeúntes de paso, no saca provecho de su posible rentabilidad, pero se integra a los flujos que atraviesan el espacio. Por lo tanto, se relaciona con "el otro" de forma horizontal, con familiaridad, de la misma forma que las comunidades indígenas cuando en la "pambamesa" comparten por igual los alimentos entre sus integrantes.

Su acción, es un mensaje más que circula en la frontera; pues ésta, como todo lugar de límite "sigue un doble juego. El límite hace lo contrario de lo 
que dice" (de Certeau, 2000, p.141). La frontera entonces posibilita la comunicación estimulando la construcción de puentes; se trata de un lugar que produce relatos e historias compartidas en un espacio caracterizado por el comercio y el intercambio; es decir, "el espacio de operaciones que produce está hecho de movimientos: es topológico, relativo a las deformaciones de figuras y no tópico, que define lugares." (de Certeau, 2000, p.141). El espacio de la frontera entonces, no tiene forma establecida, sus límites constantemente cambian; surgen puentes que, como la obra de Dalgo, deforman momentáneamente la pasajera configuración de la frontera. Recordemos que la condición espacial del eufemismo es el tiempo y esos puentes fronterizos que llevan y traen productos, así como relatos, construyen historias viajeras que se superponen a la historia oficial. Cada relato es un puente que nace en ese lugar y une por un momento lo que la historia, en mayúsculas, separó. Se trata de pequeños discursos, efímeros y pasajeros y, por ello mismo, discursos ocultos que, sin embargo, desdibujan la forma definida por el discurso oficial.

\section{Refunfuño}

Finalmente, el último ejemplo corresponde a un proyecto que muestra, en la coincidencia de su característica comunicativa y espacial, las cualidades del refunfuño. El proyecto de Andrea Zambrano, "Calzones parlantes" (2011), trata el tema de la violencia doméstica hacia las mujeres. La artista trabajó con mujeres del barrio La Venecia al sur de Quito durante tres meses. Intercambiaron anécdotas mientras trabajaban juntas en el tejido y bordado de calzones; en ellos se llegaron a leer palabras y frases que dieron cuenta de su cotidianidad con alguna forma de violencia, evidenciando a la mujer en su condición de cuerpo dominado. El proyecto se complementó con la lavandería comunitaria donde se lavaron las prendas y se expusieron al resto de la comunidad. 


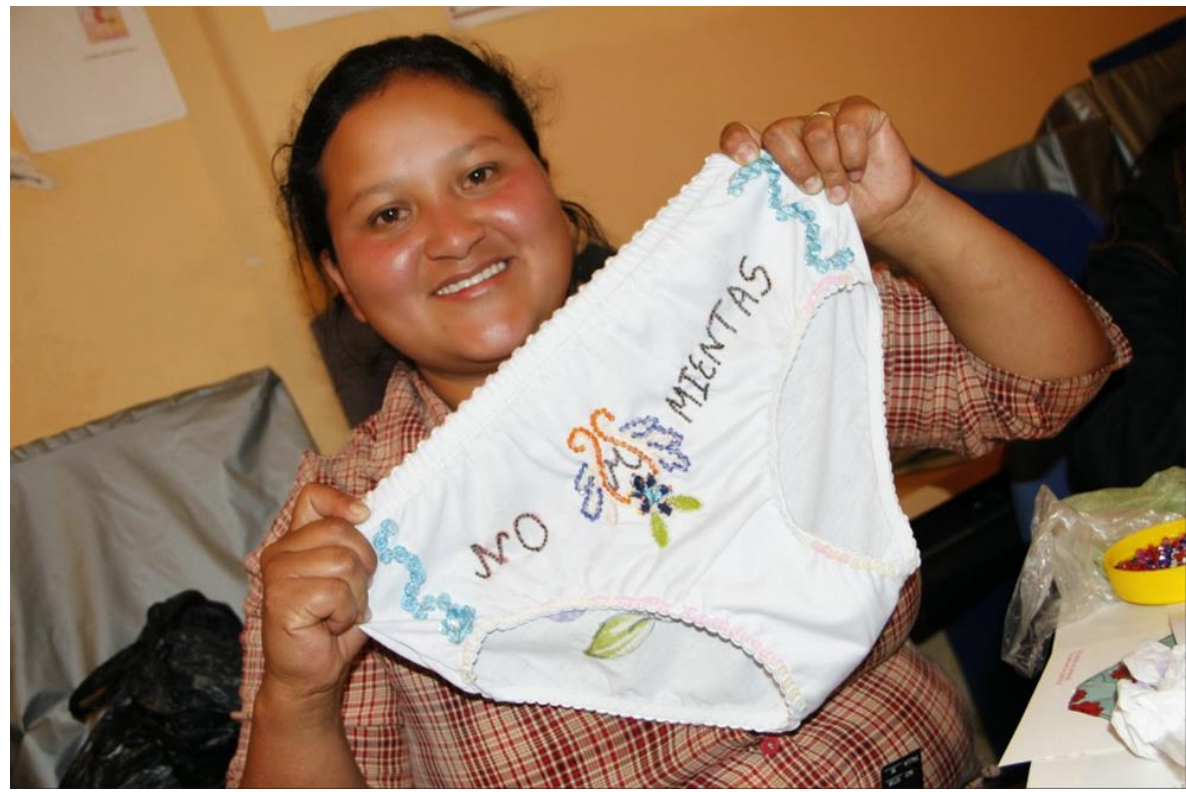

Figura 5. Calzones parlantes. Fuente: obtenido de http://arteurbanosur.blogspot.com

Partimos de que "Lo personal es político", sacamos "los trapitos al sol" porque ya no creemos que "la ropa sucia se lava en casa" nos dice la artista. Esas palabras dan cuenta de una dimensión política y pública en claro contraste con una dimensión privada e íntima del proyecto; todo ello representado en un calzón parlante. Una prenda de vestir íntima llevada al plano público donde se puede expresar y decir. Su voz se escucha y esta voz está llena de indignación, reclamo y denuncia. El arte, en este caso, se fundamenta en la experiencia de las mujeres, pues, para Rancière "La "autonomía del arte" y la "promesa de la política" no se contraponen. La autonomía es la autonomía de la experiencia, no de la obra de arte" (Rancière, 2019, p.154), Y, es que, cada una de las 15 mujeres que participaron en el proyecto expresó una historia que tenía que ver con una experiencia personal de violencia.

Zambrano con su proyecto propone una acción compartida basada en prácticas cotidianas. Como artista, está buscando una experiencia vivida y, por tanto, una experiencia relacionada con el campo del arte; en ese sentido, el proyecto decanta en una experiencia estética. Para Schiller, mencionado en Rancière (2019), toda experiencia estética tiene que ver con el "arte de vivir" y, por lo tanto, en la relación arte-vida se sostiene todo régimen sobre el arte 
o toda "política de la estética". La experiencia del "arte de vivir" "Funda la autonomía del arte hasta el punto de conectarla con la esperanza de "cambiar la vida"" (Rancière, 2019, p.152). Esa esperanza se entrevé en el proyecto de Andrea Zambrano, cuando las mujeres, a manera de petición, expresan su voz trabajada en su ropa íntima; cuando la exponen están llevando al plano estético su vida con la esperanza de cambio, tratándose por ello de una acción política.

Funciona como política la exposición que las mujeres hacen, cuando el espacio en el que la realizan no es el privado de sus prácticas cotidianas, sino, tiende a ser público. El espacio público es el espacio de lo político y por ello también es el espacio de la esperanza de "cambiar la vida". La exposición calzones parlantes (2011) pone en evidencia las dos dimensiones que, según James Scott (2000), se presentan en el despliegue de la política: una dimensión pública y una dimensión oculta de la política; a cada una de estas dos dimensiones le corresponden lenguajes, modos de actuar y prácticas distintas. Cuando la exposición de Zambrano se realiza en la lavandería del vecindario, se pone en evidencia el espacio donde las mujeres desarrollaban la dimensión oculta de la política que ahora, pasa a la dimensión pública de la misma, adquiriendo las formas públicas de una exposición de arte, entre otras cosas, debido a que el poder, siempre está simbolizándose (Scott, 2000).

Todas lavan sus prendas en la lavandería comunitaria; en ese espacio tradicional de encuentro e intercambio pueden desahogarse; ahí pueden decir aquello que resulta incómodo expresar en la privacidad del hogar e imposible mencionarlo en el espacio público; ambos espacios controlados por el hombre. Es por ello que en el intersticio de lo público y lo privado, su voz puede surgir. Por supuesto, se trata de una voz que no se guarda en la privacidad de la casa, pero tampoco se vuelve audible en el espacio público. Se trata de una voz contenida porque su decir sería reprimido en el exterior, pero, tampoco puede apaciguarse en el interior. Es voz contenida, como estrangulada en la garganta con toda la urgencia de salir. Se la escucha entonces en el espacio intermedio de lo comunitario, ahí donde se reúnen los iguales para intercambiar alegrías y desventuras, y donde, muchas veces, se denuncia la violencia. Ahí puede surgir la voz amarga de la acusación, aquella que no soporta la injusticia de la casa y se esfuerza por salir a la luz de la calle. Su significado sale desmembrado y con furia contenida pues, es la violencia quien lo engendra. Es la voz del refunfuño que habita el umbral de la locución; prohibido de expresarse, pero imposible de reprimirse. 


\section{La Necesidad del Disenso}

En la historia de los encuentros al zur-ich, la nominación y definición del evento ha ido cambiando progresivamente, ha transitado de "arte urbano" en sus inicios a "arte y comunidad" en la actualidad, pasando por nominaciones como: "arte, comunidad y espacio público" o "arte urbano y comunidad". En esa metamorfosis nominativa se puede observar, o se hace patente la distancia (ambivalente) recorrida de lo urbano a lo comunitario o rural; es decir, de la ciudad al campo pues, parecería que durante los años que lleva activo el encuentro, a la paulatina consolidación del mismo le acompañó la necesidad progresiva de alejarse de lo urbano. Transformación o evolución que busca la estabilidad y permanencia, característica propia de los roles familiares o comunitarios y que, resulta comprensible si consideramos que, -como lo advirtió Manuel Delgado (2011)- la lógica de las estructuras sociales urbanas se basa en la inestabilidad y el movimiento, encontrándose dichas estructuras en constante construcción y cambio; estructuras sociales que se configuran y consolidan cuando más cerca se encuentran de la figura institucional en la que los roles sociales están identificados y determinados.

Este cambio nominativo representa, a su vez, un traslado, no sólo en sentido metafórico, sino, espacial y relacional; rememorando, de alguna forma, la distancia esencial que Tönnies identificó en su "Comunidad y Sociedad" pues, las prácticas del "arte comunitario" se alejan de la ciudad buscando otro tipo de relación social. El arte practicado en las comunidades periféricas a la ciudad se distancia también de las galerías, museos, academias y centros de arte; es decir, de los espacios y prácticas urbanas del arte, donde los individuos, en dichas instituciones y espacios "no están esencialmente unidos, sino esencialmente separados" (Tönnies en de Marinis, 2010, p.363), pues, esos espacios terminan siendo sólo un medio para la persecución individual de fines (de Marinis, 2010, p.364). Es así que, al buscar un arte comunitario, se pretende también encontrar otro tipo de espacios y relaciones sociales horizontales, no competitivas ni jerárquicas, cuyos proyectos y fines se basen en el diálogo y el consenso. Pero, con esa práctica consensual ipuede, el arte -y en este caso, el arte comunitario- en realidad distanciarse del "todos contra todos" que su origen urbano le otorga?

A nivel regional, la pretendida inclusión social que las prácticas de arte comunitario han buscado ha sido blanco de reproches desde algunas perspectivas críticas que señalan que sus prácticas sólo buscan "extender el acceso sólo a prácticas y productos de la "alta cultura" (...) reproduciendo esquemas de dominación o, en el mejor de los casos, promoviendo la inclusión 
para unos pocos" (Wald, 2009, p. 54). Quizá por ello, los encuentros al zurich hayan evadido la nominación categórica de arte comunitario y, a su vez, hayan buscado un talante crítico insertándose en las prácticas y saberes de los grupos en los cuales actúan; de ahí la necesidad de gestionar su acercamiento a la comunidad a través del consenso. Sin embargo, en "la mayoría de convocatorias de este carácter, es fácil, por ejemplo, idealizar los métodos y los efectos de un proyecto que involucra a la comunidad" (Andrade en Almeida, 2018, p.113). Tal idealización explicaría la poca o nula continuidad de los proyectos en las comunidades y, terminaría señalando a dichos proyectos artísticos como propios de la ciudad y lo urbano, por su carácter efímero y singular; mostrando que la división entre arte y comunidad aparece, de esta manera, renovado. Así mismo, estas prácticas artísticas pueden decirnos, por otro lado, que es ficticia la existencia misma de una unidad barrial o comunitaria, e indicarían que ésta idea de unidad y comunidad respondería, más bien, a una construcción discursiva externa e ideal, promovida y llevada en este caso, por los artistas y gestores culturales.

La convocatoria, instrumento utilizado en las prácticas de arte comunitario, tiene que ver con la necesidad de participación ciudadana como mecanismo de gestión social, semejante al efectuado por las instituciones públicas para legitimar sus prácticas y estrategias de intervención, muchas de ellas, encargadas de apaciguar la crisis del espacio público. Si bien, los encuentros sociales de participación ciudadana que fomentan los proyectos de al zur-ich promueven la utilización política y democrática del espacio urbano; es necesario tomar en cuenta que, al basar su estrategia de participación ciudadana fundamentalmente en el consenso, como conciliación de todas las partes que acatan sus reglas internas, se estaría negando la cualidad misma del espacio público y de su carácter democrático como plataforma política que propicia el encuentro heterogéneo de individuos en constante negociación y dialogo; pues, "cuando el acto político, entendido como la puesta en contraste de subjetividades individuales y singulares, somete a la heterogeneidad social a un proceso simple de suma entre partes este se homogeniza" (CrespoSánchez, 2019, p.106).

Cuando en el 2003, algunos de los integrantes, de lo que sería luego Tranvía Cero, realizan su primera intervención en el espacio público delimitando el perímetro de un parque -en el sector de La Magdalena en Quitocon plástico transparente y evitando el libre acceso al mismo, lo hacen sin convocar al vecindario; simplemente "buscábamos la reflexión sobre el espacio público y la propiedad privada (...) -encontrándose, más bien, conlos habitantes del sitio furiosos" (Almeida, 2018, p.11); se trata de una 
propuesta que se encuentra en los inicios tanto como en las antípodas de lo que luego serían los encuentros de al zur-ich. En aquella propuesta "Clausurado" (2003)- la participación de la ciudadanía se fundamentó en su reacción activa, espontánea y sin intermediarios; es decir, prevaleció el disenso por sobre cualquier pretensión de consenso. Ambas partes, artistas y ciudadanía, se encontraron en el espacio abierto de la disputa y la negociación sin ningún tipo de intermediación; es decir, hicieron evidente, llevando al extremo, la condición política del espacio público. En "Clausurado" la "furia de los habitantes" mencionada por Almeida (2018) también puede demostrar lo que Jacques Rancière (2019) llama "la eficacia del disenso" pues éste "es un conflicto entre una presentación sensible y una forma de hacer sentido de ella" (Rancière, 2019, p.180) y, de esa manera, posibilita reconstruir o volver a trazar el marco que configura el sentido social de lo real; es decir, hace política. De ahí que, el disenso se encuentra en el corazón mismo de la política y "si existe alguna conexión entre el arte y la política, ésta debería expresarse en términos de disenso... Las obras de arte pueden producir efectos de disenso precisamente porque no dan lecciones ni tienen ningún destino" (Rancière, 2019, p.181) Así es como el arte, en cuanto político, se presenta como opuesto al consenso que, por el contrario, se fundamenta en "la reducción de la subjetividad y la represión de los pensamientos alternos por el bien común. Es decir, doblegar las diferencias con el fin de hacer prevalecer el interés general, imponiéndose el consenso como principio moral" (Crespo-Sánchez, 2019, p.105).

La convocatoria como instrumento que da la pauta para congregar y organizar a los individuos en pos de un bien común forma parte de las reglas internas del consenso y, por tanto, es la primera traba a la posibilidad de disenso. Los habitantes que protestaron o se incomodaron con la intervención artística de "Clausurado" no fueron convocados a ser parte del proyecto, sin embargo, complementaron el mismo, otorgándole el sentido político tanto a la obra como al espacio público. Su reacción no fue planificada ni programada, quizá, a lo sumo alimentó una sospecha; presentándose como un accidente o acontecimiento propio de las estructuras inestables de lo urbano pues:

La no dependencia de una estructura institucional fija pone en valor lo espontáneo y genuino del acto de negociar, mismo que emerge por evocación y no por convocatoria: la comunicación, el conocimiento, la conciencia, la acción y la cooperación se entienden como atributos preexistentes en el individuo, los cuales, sólo requieren de sucesos particulares que los hagan surgir. (Crespo-Sánchez, 2019, p.105) 
La trayectoria de los encuentros al zur-ich muestran entonces, un traslado de prácticas colectivas de lo público hacia lo privado; desde la irrupción casi ilegal y anónima del espacio público, hasta la norma reglamentada de alquiler simbólico de un espacio privado (como serían las residencias para artistas). Tendencia que se recrudeció con la emergencia sanitaria provocada por la pandemia del covid-19, por la que la convocatoria del 2020 denominada "reinicio" se ve obligada a tratar los aspectos urbanos y comunitarios con los protocolos y normas de seguridad que prefieren evitar el espacio público, consolidando, de esa manera el alejamiento rotundo de la calle, considerada, ahora sí, como un peligro. Entonces, si ha existido un acercamiento consiente hacia la seguridad comunitaria, formal e institucional, sostenido por el discurso del consenso en detrimento de las diferencias y antagonismos propios de lo urbano y el disenso, existe también un alejamiento de la definición de arte como práctica propia de la ciudad, practicada por individuos que, con singularidad y originalidad pretenden salir del anonimato que impone lo urbano.

Sin embargo, la búsqueda de consolidación, social e institucional del arte comunitario, parecería encontrar su contrapeso al enfrentarse con territorios de carácter fronterizo y ambiguo, donde lo rural no se muestra en una comunidad compacta sino, en una urbanidad dispersa. En ese sentido, los proyectos artísticos que allí actúan, también pueden leerse como otro disfraz -usando el término de Scott (2000)- con el que se ocultan otro tipo de mensajes. Después de todo, para Scott (2000), los dominados siempre supieron adoptar las formas y discursos hegemónicos para utilizarlos a su favor y poder expresarse en el espacio público. En ese sentido, el trabajo de artistas y gestores culturales camuflado en normas y prácticas institucionales se presentaría como la evocación -reclamada por Crespo-Sánchez (2019)- que surge a partir de algunos "sucesos particulares" que, en su acontecer, pueden sugerir discursos disidentes propios de lo urbano pero ocultos en lo comunitario.

\section{El Disfraz y su Doble Faz}

La metodología utilizada para el análisis de este estudio, primero, basada en los desplazamientos o andares que realizan los transeúntes en la ciudad, referido ello a la práctica espacial urbana analizada por Michel de Certeau y, luego, en las "formas elementales del disfraz" de James Scott (2000), nos sirvió para clasificar y categorizar los diferentes proyectos analizados. Ambos autores, de alguna manera, separan, contraponen y evidencian las tácticas y 
formas con que los individuos utilizan los discursos y espacios que condicionan o subordinan su práctica cotidiana; marcando de esa manera, siempre dos polos opuestos en constante interrelación. En esa dinámica, las interpretaciones y resultados obtenidos mostraron algunos de los traslados y desplazamientos espaciales y semánticos que ambos polos dialogantes pueden ofrecer.

Los tres casos estudiados manifiestan una condición espacial y territorial particular de las comunidades involucradas. En ellas, el traslado o desplazamiento se vuelve relevante para su práctica y posición social. Así, las trabajadoras sexuales en el proyecto de Fernando Falconí fueron obligadas a dejar el centro para ocupar una posición periférica de la ciudad. En el proyecto de Patricio Dalgo, los habitantes que comercian entre Huaquillas y Aguas Verdes constantemente deben atravezar una línea fronteriza y, en el proyecto de Andrea Zambrano, las mujeres que, sin poder dejar su espacio privado y sin poder ocupar un espacio público, logran encontrar un lugar intermedio donde expresarse. Los tres proyectos, de esa manera, se relacionan con el desplazamiento, establecimiento y rebase de límites descrito por Michel de Certeau (2000, p.136), y por ende, se trata de desplazamientos que, a su vez, ponen de manifiesto la existencia de polos apuestos, ya sea centro-periferia, nacional-extranjero o público-privado $\mathrm{y}$, ambos -los proyectos artísticos tanto como las comunidades involucradas- desarrollan sus prácticas artísticas y sociales conectando a la vez que separando dichos polos, pero siempre, manifestando que éstos no son homogéneos ni equidistantes, sino que, se fortalecen por relaciones de poder que los tensan y desequilibran constantemente, señalando, de alguna forma, la desigualdad social existente.

El espacio fronterizo en el que el arte comunitario actúa entonces, es un espacio de equilibrio inestable, en el que los roles sociales y artísticos se mezclan y confunden mientras dura su revelación. Para las comunidades involucradas, estas tres formas de desplazamiento, representan la necesidad, obligatoriedad o circunstancia de encontrarse, eventualmente, camufladas u ocultas en el territorio social: las trabajadoras sexuales son desplazadas para no ser vistas; los habitantes de la frontera Ecuador-Perú comercian en una línea imaginaria y las mujeres de La Venecia deben ocultarse para poder expresarse. Esta exposición camuflada o condicionada provoca el surgimiento de "tácticas" y "formas" de ocultamiento/develamiento en el espacio social. Es el "disfraz" y su juego ambivalente entre ocultar-mostrar, la condición necesaria y cotidiana con que algunas comunidades habitan políticamente el espacio. El arte, en esas circunstancias, simplemente juega con las máscaras que ya existen en la sociedad. 
El traslado y la transitoriedad, sumado al disfraz o la "máscara" social, son señas particulares que comparten comunidades y arte comunitario. Por tanto, comparten características propias de lo urbano. Es decir, el espacio fronterizo entre la ciudad y el campo sería un espacio urbano en el que lo rural se disuelve o, más bien, un espacio rural urbanizado; en este caso, a través de prácticas artísticas y, por tanto, prácticas urbanas que se desplazan y camuflan en las comunidades; prácticas que urbanizan su espacio mientras se hibridan momentáneamente con ellas; encuadrándose sin remedio, pero, a regañadientes, en el marco global del "multiculturalismo" y, por lo mismo, disintiendo de forma camuflada a través de la evocación de algunos proyectos artísticos.

\section{Referencias}

Almeida, P. [comps.] (2018). Al zur-ich, más que un proyecto, un recurso estratégico. Quito: Universidad Central del Ecuador.

Almeida, P. (s.f.) Ver. Encuentro al zur-ich. http://arteurbanosur.blogspot.com/

Ardenne, P. (2006). Un arte contextual. CENDEAC.

Arendt, H. (2016). La condición humana. Paidós.

Bauman, Z. (2007). Arte, ¿Líquido? Ediciones Sequitur.

Bishop, C. (2006). "The social turn: Collaboration and Its Discontents." Artforum.

Bourriaud, N. (2008). Estética relacional. Adriana Hidalgo editora S.A.

Comaroff, J. (2011). Etnicidades S.A. Kantz.

Crespo-Sánchez, C. A. (2019). "El disenso en los procesos de participación ciudadana. El rescate de espacios públicos como contexto". Bitácora $\begin{array}{llll}\text { Urbano } & \text { Territorial, } & 29 & \text { (3): }\end{array}$ https://doi.org/10.15446/bitacora.v29n3.70146

De Certeau, M. (2000). La invención de lo cotidiano. Cultura libre.

De Marinis, P. (2010). Sociología clásica y comunidad: entre la nostalgia y la utopía (un recorrido por algunos textos de Ferdinand Tönnies). En P. De Marinis, G. Gatti, I. Irazuzta (Eds.), La comunidad como pretexto. En torno al (re)surgimiento de las solidaridades comunitarias (pp.347-382). Anthropos.

Delgado, M. (2007). Sociedades movedizas. Anagrama.

Delgado, M. (2011). El espacio público como ideología. Catarata.

Durkheim, E. (2014). La división del trabajo social. Ediciones LEA

Echeverría, B. (2010). Definición de la Cultura. Fondo de Cultura Económica. 
Gadamer, H. (1991). La actualidad de lo bello. Ediciones Paidós.

García Canclini, N. (1989). "El debate posmoderno en Iberoamérica." Cuadernos Hispanoamericanos 463, 79-92.

Goffman, E. (1997). La presentación de la persona en la vida cotidiana. Amorrortu.

Gómez, S. (2001). “¿Nueva ruralidad? Un aporte al debate.” Estudos Sociedade e Agricultura 17, 5-32

González, M. (2012). "Identidades y conflictos en territorios de frontera ruralurbana." Eutopía 3, 95-115

Greco, Á. (2007). La Red Americana de Arte para el Cambio Social: cuando la resistencia a las políticas neoliberales viene desde el Arte. Un análisis interdisciplinario sobre sus orígenes y dinámicas. Tesis de Maestría sin publicar. FLACSO.

Han, B. (2018). La salvación de lo bello. Herder.

Kay, C. (2007). "Algunas reflexiones sobre los estudios rurales en América Latina." Íconos 29, 31-50.

Kingman Garcés, E. y Bretón, V. (2016). "Las fronteras arbitrarias y difusas entre lo urbano-moderno y lo rural-tradicional en los Andes." The Journal of Latin American and Caribbean Anthropology 22, 235-253. https://doi.org/10.1111/jlca.12216

Kingman Garcés, E. (2006). La ciudad y los otros. Quito, 1860-1940. FLACSO.

Kingman Garcés, E. (2016). Trajines callejeros: ciudad, modernidad y mundo popular en los Andes (años 1940 y 1950) En A. Gorelik y F. Areas Peixoto. (comps.) Ciudades sudamericanas como arenas culturales. Siglo veintiuno editores.

López A. y Bermúdez R. (2018). “¿Pero esto qué es? del arte activista al activismo artístico en américa latina, 1968-2018." El Ornitorrinco Tachado. Revista de Artes Visuales 8, 17-28.

Massey, D. (2008). "Geometrías internacionales del poder y la política de una "ciudad global": pensamientos desde Londres." Cuadernos del CENDES 25, 115-122.

Michaud, Y. (2007). El arte en estado gaseoso. Ensayo sobre el triunfo de la estética. México: Fondo de Cultura Económica.

Morgan, S. (1995). “Looking back over 25 years", en Dickinson, M. (ed.), Art with People. AN Publications.

Lefebvre, H. (1978). De lo rural a lo urbano. Barcelona: Península.

Palacios, A. (2009). "El arte comunitario: origen y evolución de las prácticas artísticas colaborativas." Arteterapia 4, 197-211. 
Rancière, J. (2019). Disenso. Ensayos sobre estética y política. Fondo de Cultura Económica.

Segura-Cabañero, J. y Simó Mulet, T. (2017). “Espacialidades desbordadas." Arte, Individuo y Sociedad 29, 219-234.

Scott, J. (2000). Los dominados y el arte de la resistencia. Ediciones Era.

Simmel, G. (1977). "La metrópolis y la vida mental”, en Revista Discusión núm. 2. Barral.

Soja, E. (2008). Postmetrópolis. Estudio crítico sobre las ciudades y las regiones. Edición traducida y digitalizada por Traficantes de Sueños.

Tranvía Cero (2013). Ver. Catálogo al zur-ich 2003-2013.

Wald, G. (2009). "Los dilemas de la inclusión a través del arte: tensiones y ambigüedades puestas en escena." Revista Oficios Terrestres 53-63.

Kléver Vásquez Vargas: Architect and professor at the Faculty of Architecture and Urbanism of the Central University of Ecuador (UCE). He completed postgraduate studies in Logic and Technique of Form at the University of Buenos Aires (UBA); Theory and Practice of the Architecture Project at the Polytechnic University of Catalonia (UPC) and City, Territory and Sustainability at the University of Guadalajara (UDG). He is a founding member of ALEPH (Latin American Association for Studies of Form) based in Buenos Aires. He is the editorial director of the magazine "Arquitectura $y$ Sociedad" (UCE) and guest editor of the magazine "Corazonada" (UBA).

Email address: kfvasquez@uce.edu.ec

Contact Address: Central University of Ecuador, Faculty of Architecture and Urbanism. Av. Universitaria, Quito 170129 Ecuador. 